\title{
Analysis on Construction Technology Management Strategy of Power Transmission Line
}

\author{
Guizhu Song \\ Dezhou Power Supply Company Shandong Dezhou 253008, China
}

\begin{abstract}
: with the rapid development of economy, people's demand for electric power is increasing, and the number of electrical equipment is gradually increasing, and the technical requirements are also gradually increasing, which also brings challenges to transmission lines. Strengthen the construction technology and management specification of transmission line, formulate construction scheme and measures according to different terrain, terrain and specific situation, and operate efficiently and strengthen management. Keywords: Power transmission line; Power engineering; Technical management
\end{abstract}

Citation: Song Guizhu, 2019. Analysis on Construction Technology Management Strategy of Power Transmission Line. Journal of Smart Cities, 4(1): 10-12. http://doi.org/10.26789/JSC.2019.01.004

Copyright: Analysis on Construction Technology Management Strategy of Power Transmission Line. C 2019 Song Guizhu. This is an Open Access article published by Urban Development Scientific Publishing Company. It is distributed under the terms of the Creative Commons Attribution-Noncommercial 4.0 International License, permitting all non-commercial use, distribution, and reproduction in any medium, provided the original work is properly cited and acknowledged.

\section{Introduction}

In the process of power system construction, transmission line construction technology plays a very important role in determining the speed and quality of power construction projects. Hot issue in recent years into intelligent power system reform, change the traditional transmission line construction technology, to provide power resources guarantee for national economic development, transmission lines is mainly long distance power transmission, is between substation, substation and power plants, the user contact line between important in construction quality and the efficiency of the supply of electricity, In this paper, based on the actual situation, effectively solve the various problems existing in the power system, in-depth introduction of the development of power enterprises may exist related problems, the complexity of related technology and the development of advanced methods, efficient and rapid supply of electricity for the whole society has become the primary development direction of the power system.

\section{Development of transmission line construction technology in electric power engin- leering}

\subsection{Survey of electric power transmission lines}

Survey in electric power engineering electric power transmission line is the first preparation of transmission line construction, need to survey the staff has a great sense of responsibility and patience, for different terrain in-depth survey, according to the landmark point mark, in order to make the transmission line survey, better security, need at any time and the development of transmission line design personnel to communicate, According to the different terrain and the distance of the transmission line laying, formulate specific the construction plan, comprehensive consideration of possible problems in the construction process, and try to solve the problem before the construction, overcome difficulties and ensure the construction process of resistance as small as possible, in the process of transmission line survey, to protect important landmarks terrain, will power and economic development closely linked, Generally, the laying of long-distance power transmission lines involves a wide range of areas, so it takes a long time to survey the transmission lines. The more sufficient the preliminary preparation is, the more favorable the laying of transmission lines for the subsequent construction.

\subsection{Construction technology development of tower erection}

The erection of long distance power transmission lines requires the erection of multiple towers. The successful erection of the tower is mainly related to two aspects. The first is the quality problem of the tower itself on the one hand, selection of tower, the first thing to ensure the qual- 
ity of a material is solid, basic resistance to bad environment under external force for the destruction of the poles, fully able to transmission lines under the pressure, the second is the foundation of the tower construction, the need to guarantee the poles foundation deep, avoid the storm wind environment, due to the unstable poles foundation collapsed, Then cause power system accidents, affect the normal operation of the power grid. The second aspect is that the material selection of the tower is closely related to the natural environment. In different sections and natural environment, it is necessary to choose the corresponding material of the tower. Four seasons environment and wind less influence of the plain area, you can directly use Angle steel tower and steel pipe, and in the less developed traffic in mountainous areas, can not ensure maintenance at any time, need to erect more solid mechanical properties of higher Angle steel tower and steel pipe, iron material tower.

\subsection{Line construction technology development}

Current wiring project can be done by machine transmission and delivery, but need a lot more of the prophase preparation, for transmission lines in power transmission line survey personnel after an in-depth survey, by the department of surveying and mapping mapping accordingly plot, according to the diagram at the designated site wiring, mainly through three aspects: pay-off, wires and tight line. The efficiency of manual routing is low, and the labor cost is large, and the possibility of wiring in mountainous areas with steep terrain is small, so the machine routing is selected to brake through the generator, and the transmission line is put in and laid, which greatly improves the efficiency of the wiring project, but it is still to be developed to be applicable to every kind of terrain.

\section{Electric power transmission system construction technology management}

\subsection{Strengthen the management of the construction site}

In the construction site mainly for the safety of construction personnel, the quality of equipment and the quantity of materials to manage, strictly control the use of materials and personnel in and out, in the premise of ensuring the personal safety of construction personnel, speed up the construction progress. In terms of wiring and other aspects, it is a long distance work, and usually carried out in the field, especially in mountainous areas and other steep terrain, the difficulty of work will be greatly increased, but in order to ensure the comprehensive coverage of the power system, to overcome the problems brought by environmental factors. Establishing and perfecting the supervision and responsibility system, strengthen the contracting businesses for the safety of construction process and material distribution regulation, to ensure the safety and rationality in the process of electric power transmission system construction, relevant staff must pass strict training or preparations for the job, to do related certificates, for the high risk of power transmission system operation, To ensure that at least two or more technical staff operate at the same time, timely response to emergencies in the construction process.

\subsection{Construction quality control in electric power transmission system}

In the installation process of transmission line auxiliary facilities, it is necessary to strictly control the installation quality to ensure that the transmission line is fixed well and avoid loosening phenomenon. Line pressing process generally choose line pressing machine, but is the special terrain, the machine can't match under the condition of transmission lines, can use artificial line pressing, also need to pay attention to the material of transmission line problems, take cover engineering personnel should strengthen quality control, for the tower, ground wire, estimation of insulator, hardware and other construction materials, avoid to cause waste. In addition, the maintenance frequency of the power system should be appropriately increased in the rainy season, so as not to rust the metal tower rod and affect the bearing effect.

\section{Conclusion}

The development trend indicates that the power system operation technology will be innovated in the future to ensure the stable development of transmission lines and achieve the purpose of efficient power supply. Power transmission system related construction policies need to be further improved, in the future work to continue to improve, in order to build a better transmission line construction system. Also gradually increase to the requirement of electric power system industry, the different situation of transmission line construction difficulty, want to consider the natural environment and terrain conditions, and many other factors, to ensure power engineering in the construction of transmission line under the premise of the quality pass, you need to formulate the perfect solution in advance, and to properly manage and run, improve the efficiency of construction, starting from the team management, From the information exchange to determine the period requirements, all departments cooperate with each other to complete the transmission line construction work 
in time. According to the specific construction situation, the construction strategy of transmission line is changed to increase the reliability of construction and improve the safety factor. This paper mainly analyzes the construction technology of $220 \mathrm{kV}$ conventional transmission lines, conducts in-depth analysis of transmission line construction technology and management methods in power engineering, and provides a certain theoretical basis for the innovation of transmission line construction mode in the future.

\section{References list:}

[1] Wu Linzhi, Zhang Cheng. Science \& Technology Economic Guide. 2020(05)

[2] Nie Qingtao. China Equipment Engineering. 2020(14)

[3] Analysis on Matters needing attention for $220 \mathrm{kV}$ and below transmission line Construction $[\mathrm{J}]$. Duan Zhizhong. Electronic Components and Information Technology. 2020(06) 